\title{
Microbial Biocompatibility and Biodegradability of Choline-Amino Acid Based Ionic Liquids
}

Arash Yazdani ${ }^{1,3}$, Magaret Sivapragasam ${ }^{1}$, Jean-Marc Levêque ${ }^{1,2 *}$ and Muhammad Moniruzzaman ${ }^{1,3 *}$

${ }^{1}$ Centre of Research on Ionic Liquid (CORIL), Universiti Teknologi PETRONAS, 32610, Bandar Seri Iskandar, Perak, Malaysia ${ }^{2}$ LCME/SCeM, Université de Savoie Mont-Blanc; 73376 Le Bourget du Lac cedex, France

${ }^{3}$ Department of Chemical Engineering, University Teknologi PETRONAS, 32610, Bandar Seri Iskandar, Perak, Malaysia

\begin{abstract}
Choline-Amino acid based ionic liquids (AAIL) have sparked recent interest throughout the scientific community due to their allegedly low cost and natural origin. They are considered as a potential "green" solvent to replace conventional volatile organic solvents. However, much is still scarce on their (AAILs) microbial toxicity and biodegradability. This study reports the synthesis of ten AAILs with cholinium cation and variable anions derived from amino acids. Their microbial biocompatibility to gram-positive (Bacillus licheniformis and Staphylococcus aureus) and gram-negative (Pseudomonas aeruginosa and Vibrio cholerae) bacteria and biodegradability by industrial sewage water were analyzed. All the tested AAILs were reported to have $\mathrm{EC}_{50}$ values in the range of 160-1120 mg/L which is deemed "practically harmless" based on hazard rankings. The toxicity trend was seen to reduce as the molecular weight of the anion decreased. The level of mineralization of AAILs through anaerobic microbial breakdown was found to be a factor of anion and its functional group in all the cases. They resulted to over $60 \%$ biodegradation in 28 days (readily biodegradable).
\end{abstract}

Keywords: Amino acid, ionic liquids; Biodegradability; Microbial toxicity

\section{Introduction}

Ionic liquids (ILs) are commonly referred to as liquid salts, comprising of anions and cations. Since the past few decades, there has been growing attention towards these new "green" solvents and their applications due to their impressive physicochemical properties such as low boiling point, low vapor pressure, thermal and chemical stability or as reviewed by numerous authors [1-5]. ILs possesses a number of advantages over conventional solvents [6] and supercritical fluids [7]. Hence, ILs has been used in different aspects of chemical engineering [8-11], nanotechnology [12], biotechnology [1,13-16] and in the pharmaceutical industry [17-22]. ILs is often characterized by their degree of biocompatibility and biodegradability, a measure which reveals the toxicity and environmental adaptability of ILs. Introducing new applications of ILs in large scale requires consideration not only on the process itself but also evaluation on their potential hazard to the environment. Biocompatibility and biodegradability are characteristics of ILs that tie them up with their practicality in actual chemical and pharmaceutical processes. Thus an ideal IL would be defined as possessing both the aforementioned characteristics while maintaining their unique properties.

The role of amino acids in synthesizing ILs can be found by recognizing their biodegradability and bioactivity features [23]. They are known to possess an improved biodegradability $[24,25]$ and enhanced biocompatibility $[24,26]$. The other advantages of amino acids are that they are available at relatively low costs [27] and can be obtained in large quantities with high purity [28]. Nevertheless, many factors still affect properties of ILs such as types of cations and anions $[29,30]$ and also the alkyl-chain length [31]. Since amino acid molecules consist of two functional groups- carboxylic acid and an amino group, they can be used as a cation or an anion in forming unique IL molecules [32]. It is well-known that using different amino acids as cation or anion would change the physicochemical and biological properties of ILs [33-35]. The toxicity mechanism of ILs on microorganism is still a vague process, but it has been suggested that the cation of the ILs permeates the cell structure, subsequently disrupting the microbial membrane [36]. As one of the approaches to find a trend in property changes with altering molecular structure of ILs, molecular engineering can be employed in order to improve toxicity and environmental acceptability (with appropriate choice of cation and anion) [37]. Choline is an essential micronutrient in living organisms involved in many physiological processes such as metabolism and transport of lipids [38] and it is proven to increase the biodegradability [39] and lower the toxicity to an acceptable range [29]. Recent studies have shown that cholinium based ionic liquids significantly improved the cytotoxicity [40], biodegradability and biocompatibility $[24,41]$ towards microorganisms.

This work aims to synthesize AAILs and investigate their biocompatibility using an eco-toxicity test on two types of grampositive (Bacillus licheniformis and Staphylococcus aureus) and gramnegative (Pseudomonas aeruginosa and Vibrio cholerae) bacteria; then to assess their biodegradability by industrial sewage water microorganisms. In order to evaluate the AAILs' toxicity, minimum inhibitory concentration (MIC) and effective concentration $\left(\mathrm{EC}_{50}\right)$ are measured.

*Corresponding author: Jean-Marc Levêque, LCME/SCeM, Université de Savoie Mont-Blanc; 73376 Le Bourget du Lac cedex, France, Tel: +605-368 7572; Fax: +605-365-251-6176; E-mail: jean-marc.leveque@univ-smb.fr

Muhammad Moniruzzaman, Centre of Research on lonic Liquid (CORIL), Universiti Teknologi PETRONAS, 32610, Bandar Seri Iskandar, Perak, Malaysia, Tel: +605368 7572; Fax: +605-365-251-6176; E-mail: m.moniruzzaman@petronas.com.my

Received September 04, 2016; Accepted September 21, 2016; Published September 28, 2016

Citation: Yazdani A, Sivapragasam M, Levêque JM, Moniruzzaman M (2016) Microbial Biocompatibility and Biodegradability of Choline-Amino Acid Based Ionic Liquids. J Microb Biochem Technol 8: 415-421. doi: 10.4172/1948-5948.1000318

Copyright: ๑ 2016 Yazdani A, et al. This is an open-access article distributed under the terms of the Creative Commons Attribution License, which permits unrestricted use, distribution, and reproduction in any medium, provided the original author and source are credited. 


\section{Materials and Methods}

\section{Synthesis of AAILs}

In this experiment, 10 ILs were synthesized by acid-base neutralization. The cation was cholinium based and the anion derived from amino acids $[\mathrm{AA}]$ or as depicted in Figure 1. The choline component of the ILs were obtained from choline hydroxide $45 \%$ in methanol and reacted with $15 \%$ excess amino acid dissolved in methanol via neutralization process for 2 days. The solvents and produced water were separated from IL ([Cho][AA]) by rotary evaporator and moisture vacuum. Ten amino acids namely L-Alanine, L-Arginine, L-Asparagine, L-Glutamine, L-Histidine, L-Methionine, L-Phenylalanine, L-Serine, L-Tryptophan and L-Tyrosine were used to synthesize AAILs. These AAILs were analyzed by $1 \mathrm{H}-\mathrm{NMR}$ spectra at frequency of $500 \mathrm{MHz}$ using deuterium oxide $\left(\mathrm{D}_{2} \mathrm{O}\right)$ as solvent.

\section{Minimum inhibitory concentration (MIC)}

The AAILs were assayed for anti-microbial activity against 4 microbial isolates obtained from the Institute of Medical Research (IMR), Kuala Lumpur, Malaysia and American Type Culture Collection (ATCC). They were Bacillus licheniformis (ATCC 14580), Staphylococcus aureus S38, Vibrio cholerae V 148 and Pseudomonas aeruginosa P20. MIC was determined using the broth microdilution method (CLSIM07-A9, 2008) [42], developed by the Clinical and Laboratory Standards Institute (CLSI), Pennsylavania, USA. Two-fold, seriallydiluted AAILs were dispensed into each of the 96 wells of a standard microdilution plate. The direct colony suspension method was used for inoculum preparation. Bacterial suspension was prepared by direct transfer of colonies from $24 \mathrm{~h}$ Mueller Hinton $(\mathrm{MH})$ agar plates to $\mathrm{MH}$ broth. Bacterial suspensions were adjusted using bacterial counting

\section{Choline Cation}

$\left[\left.\right|_{\mathrm{CH}}\left[\mathrm{Ch}_{3}\right.\right.$<smiles>C[C@H](N)C(=O)ONC(=N)NCCC[C@H](N)C(=O)O</smiles>

L-Alanine

L-Arginine

L-Asparagine<smiles>CSCC[C@H](N)C(=O)O</smiles>

L-Glutamine

L-Histidine

L-Methionine<smiles>N[C@@H](Cc1ccccc1)C(=O)O</smiles>

L-Phenylalanine

$$
\text { L-Serine }
$$

L-Tryptophan<smiles>N[C@@H](Cc1ccc(O)cc1)C(=O)O</smiles>

L-Tyrosine

Figure 1: Structure of the cations and anions in AAILs. 
chamber to contain approximately $1 \times 10^{8} \mathrm{CFU} / \mathrm{mL}$. A $100 \mu \mathrm{L}$ volume of each bacterial suspension was mixed with $100 \mu \mathrm{L}$ serially diluted tested compound in 96 microdilution plate according to the microdilution method. Uninoculated wells were prepared as control samples. Plates were incubated at $37^{\circ} \mathrm{C}$ for $24 \mathrm{~h}$ for Staphylococcus aureus S38, Vibrio cholerae V 148, Pseudomonas aeruginosa $\mathrm{P} 20$ and $30^{\circ} \mathrm{C}$ for Bacillus licheniformis (ATCC 14580). The minimum (inhibitory) bacteriocidal concentration was defined as the lowest concentration of test compound producing no visible growth. Confirmation for MIC was achieved by transfer of aliquots from wells containing no growth on to nutrient agar plates and tested for colony formation upon sub culturing. Given values of obtained MIC values are means of three independent experiments.

\section{Biodegradability test}

Biodegradability test was performed according to procedures described by Organization for Economic Cooperation and Development (OECD) 301 for Closed Bottle Test [42] using a BOD measurement system (OxiTop-C thermostatically controlled BOD meter from WTW $\mathrm{GmbH}$, Weilheim, Germany). Seeding water sample as the source of biodegradation was taken from an industrial sewage pond in Seri Iskandar, Perak, Malaysia. The dilution water was prepared and mineral medium were added according to the standard procedure and mixed with appropriate amounts of AAILs. Three replicates were prepared for each substance of test, and since it was expected to have a high degree of biodegradation, the samples were introduced with a dilution factor of 10 and oxygen demand limit of $2000 \mathrm{mg} / \mathrm{L}$, manipulated in the settings of OxiTop apparatus. A set of blank test was prepared by adding $5 \mathrm{~mL}$ of seed in a fresh medium. Biodegradability is assessed by calculating the percentage oxygen uptake of the theoretical oxygen uptake (ThOD) after 28 days. The results were compared with the ThOD in order to determine the biodegradability of the ILs.

\section{Results}

\section{Synthesis of AAILs}

AAILs were synthesized in acceptable yields and1H-NMR analysis was performed to verify their structure.

[Cho][Ala]: 1H-NMR (500 MHz, D2O) $\delta 3.92(2 \mathrm{H}, \mathrm{sep}), 3.37(2 \mathrm{H}$, quin), $3.21-3.16(1 \mathrm{H}, \mathrm{m}), 3.07(9 \mathrm{H}, \mathrm{s}), 1.08(3 \mathrm{H}, \mathrm{d})$

[Cho][Arg]: 1H-NMR (500 MHz, D2O) $\delta 3.79(2 \mathrm{H}, \mathrm{sep}), 3.42(1 \mathrm{H}$, q), $3.19(2 \mathrm{H}, \mathrm{t}), 3.12(1 \mathrm{H}, \mathrm{s}), 3.02(13 \mathrm{H}, \mathrm{s}), 0.97(1 \mathrm{H}, \mathrm{t})$

[Cho][Asp]: 1H-NMR (500 MHz, D2O) $\delta 3.89(2 \mathrm{H}, \mathrm{sep}), 3.41(1 \mathrm{H}$, q), $3.35(2 \mathrm{H}, \mathrm{t}), 3.04(9 \mathrm{H}, \mathrm{s}), 2.52-2.48(1 \mathrm{H}, \mathrm{m}), 2.28-2.23(1 \mathrm{H}, \mathrm{m})$

[Cho][Glu]: 1H-NMR (500 MHz, D2O) $\delta 3.75$ (2H, sep), $3.38(1 \mathrm{H}$, q), $3.32(2 \mathrm{H}, \mathrm{t}), 2.94(9 \mathrm{H}, \mathrm{s}), 2.32(2 \mathrm{H}, \mathrm{t}), 1.93-1.79(1 \mathrm{H}, \mathrm{m}), 1.47-1.44$ $(1 \mathrm{H}, \mathrm{m})$

[Cho][His]: 1H-NMR (500 MHz, D2O) $\delta 7.45(1 \mathrm{H}, \mathrm{s}), 6.70(1 \mathrm{H}$, s), $3.82(2 \mathrm{H}, \mathrm{sep}), 3.28(3 \mathrm{H}$, quin), $2.96(9 \mathrm{H}, \mathrm{s}), 2.77-2.73(1 \mathrm{H}, \mathrm{m})$, $2.28-2.23(1 \mathrm{H}, \mathrm{m})$

[Cho][Met]: 1H-NMR (500 MHz, D2O) $\delta 3.93(2 \mathrm{H}$, sep), $3.39(2 \mathrm{H}$, quin), $3.20(1 \mathrm{H}, \mathrm{q}), 3.07(9 \mathrm{H}, \mathrm{s}), 2.43(2 \mathrm{H}, \mathrm{t}), 1.99(3 \mathrm{H}, \mathrm{s}), 1.86-1.76(1 \mathrm{H}$, $\mathrm{m}), 1.71-1.65(1 \mathrm{H}, \mathrm{m})$

[Cho][Phe]: 1H-NMR (500MHz, D2O) $\delta 7.26-7.16(5 \mathrm{H}, \mathrm{m}), 3.89$ $(2 \mathrm{H}, \mathrm{sep}), 3.38(2 \mathrm{H}$, quin $), 3.20(1 \mathrm{H}, \mathrm{d}), 3.07(9 \mathrm{H}, \mathrm{s}), 2.89-2.83(1 \mathrm{H}, \mathrm{m})$, $2.74-2.70(1 \mathrm{H}, \mathrm{m})$

[Cho][Ser]: 1H-NMR (500 MHz, D2O) $\delta$ 3.85(2H, sep), 3.65 $(1 \mathrm{H}, \mathrm{q}), 3.52(2 \mathrm{H}, \mathrm{t}), 3.28(9 \mathrm{H}, \mathrm{s}), 1.76-1.72(1 \mathrm{H}, \mathrm{m}), 1.67-1.64(1 \mathrm{H}, \mathrm{m})$
[Cho][Trp]: 1H-NMR (500 MHz, D2O) $\delta 7.58(1 \mathrm{H}, \mathrm{d}), 7.35(1 \mathrm{H}$, d), $7.08(2 \mathrm{H}, \mathrm{t}), 7.03(1 \mathrm{H}, \mathrm{t}), 3.80(2 \mathrm{H}, \mathrm{sep}), 3.42(1 \mathrm{H}, \mathrm{q}), 3.20(2 \mathrm{H}$, quin), 3.06-3.03 (1H, m), 2.91-2.84 (10H, m)

[Cho][Tyr]: 1H-NMR (500 MHz, D2O) $\delta 6.90(2 \mathrm{H}, \mathrm{d}), 6.54(2 \mathrm{H}$, d), $3.89(1 \mathrm{H}, \mathrm{d}), 3.35(2 \mathrm{H}$, quin), $3.17(2 \mathrm{H}, \mathrm{d}), 3.04(9 \mathrm{H}, \mathrm{s}), 2.80-2.76$ $(1 \mathrm{H}, \mathrm{m}), 2.63-2.51(1 \mathrm{H}, \mathrm{m})$

\section{Minimum inhibitory concentration}

We have examined the potential ecotoxicity of the ten ILs towards 4 different microorganisms. Two of the bacteria being gram positive (Staphylococcus aureus and Bacillus licheniformis) and another two being gram negative (Vibrio chlorae and Pseudomonas aeruginosa). It is interesting to note that $B$. licheniformis and $P$. aeruginosa are bacterium that produces biosurfactants. For all ILs tested, dose response curves were obtained and $\mathrm{EC}_{50}$ values were calculated in $\mathrm{mg} / \mathrm{L}$. In this study, viability of microorganism (in \%) after $24 \mathrm{~h}$ were used as a measure of the $\mathrm{EC}_{50}$ values. Table 1 shows the $\mathrm{EC}_{50}$ values with respective 95 percent confidence level obtained in the fit of data. The effective concentrations as well as the upper and lower limit of analyzed data are illustrated in the Table 1 with indications being, the higher the $\mathrm{EC}_{50}$ value, the least toxic the AAILs. The highest $\mathrm{EC}_{50}$ value obtained was for Cho[Ala] which showed a toxicity value of $1120 \mathrm{mg} / \mathrm{L}$ (50\% inhibition) against $V$. cholerae. Cho[Tyr], on the other hand, was seen to be the most toxic towards B. licheniformis with $\mathrm{EC}_{50}$ values of $160 \mathrm{mg} / \mathrm{L}$.

\section{Biodegradability evaluation}

The evaluation of the biodegradability potential of the studied AAILs was given in Table 2 . The values represent the mineralization efficiency of a given AAILs. The biodegradation was carried out over the span of 28 days. The AAILs were inferred to be "readily biodegradable" as all the ILs achieved more than $60 \%$ biodegradation against the Theoretical Oxygen Demand (ThOD). The highest overall biodegradation (\%) value of AAILs were given in the order of; $\mathrm{Cho}[\mathrm{Trp}]>\mathrm{Cho}[\mathrm{Glu}]>\mathrm{Cho}[\mathrm{A}$ $\mathrm{rg}]>\mathrm{Cho}[\mathrm{Asp}]>\mathrm{Cho}[\mathrm{Phe}]>\mathrm{Cho}[\mathrm{Tyr}]>\mathrm{Cho}[\mathrm{His}]>\mathrm{Cho}[\mathrm{Ser}]>\mathrm{Cho}[\mathrm{Met}]>$ Cho[Ala]. The highest and lowest level of biodegradation of $85.8 \%$ and $64.1 \%$ was observed with Cho[Trp] and Cho[Ala], respectively.

\section{Discussion}

Measure of ILs' toxicity was based on the parameters by Passino and Smith in [43] who rank toxicity to be; $100-1000 \mathrm{mg} / \mathrm{L}^{-1}$ as being practically harmless, $10-100 \mathrm{mg} / \mathrm{L}$ as being moderately toxic, $1-10$ $\mathrm{mg} / \mathrm{L}$; slightly toxic and $0.1-1 \mathrm{mg} / \mathrm{L}$ being highly toxic. The data in Table 1 show the measured $\mathrm{EC}_{50}$ values vary between $160 \mathrm{mg} / \mathrm{L}$ (toxic) and $1120 \mathrm{mg} / \mathrm{L}$ (least toxic). As it was expected from using biomaterials (amino acid) derived cations and choline anion, biocompatibility of ILs were in acceptable ranges labelling them as "readily biodegradable" and "practically harmless". These results were indeed supported by many research groups $[36,29,44]$ in the past. The amino acid based anion in the structure of ILs highly improved the toxicity of the ILs- making it less toxic; although the individual data were dependent on the type of bacteria as another factor. The specific mechanism of toxicity are not well understood however there are several explanations that unravel microbial response in the presence of ILs, such as the modifications of membrane permeability, increase in osmotic pressure, enzyme detoxification or the synthesis of metabolites (allowing the entrapment of the contaminant, both extracellular and intracellular) $[36,45,46]$. Biological membranes, such as bacterial surfaces (being non-polar interfaces), has the ability to be disrupted by a hydrophobic/ionic adsorption phenomenon at the cell-membrane interface which then generates various responses towards ILs. As the nature of the gram- 
negative bacteria supposes, $V$. cholerae was more viable towards the tested AAILs in comparison with S. aureus and B. licheniformis. This can be clearly seen in the respective $\mathrm{EC}_{50}$ value of every tested AAIL. Cho[Tyr] which has a comparably larger anion molecule shows a higher toxicity with an $\mathrm{EC}_{50}$ value of $160 \mathrm{mg} / \mathrm{L}$ towards $B$. licheniformis compared to other AAILs, then followed by Cho[Trp] and Cho[Phe] with $\mathrm{EC}_{50}$ value of 194 and $217 \mathrm{mg} / \mathrm{L}$ respectively. The least toxic IL to this type of bacteria is found to be Cho[Asp] with $\mathrm{EC}_{50}$ value of 588 $\mathrm{mg} / \mathrm{L}$ followed by Cho[Ala] $(474 \mathrm{mg} / \mathrm{L})$ and Cho[Met] $(417 \mathrm{mg} / \mathrm{L})$. It is necessary to mention that not all of the tested AAILs are "harmless" but they can be considered as "practically harmless" (>100 mg/L) [43] to $B$. licheniformis which is the most sensitive bacterium in this study. Also noteworthy, B. licheniformis and P. aeruginosa were chosen as bacteriasubclass producing surfactants. They represent the class of bacteria that produce biofilms and have widely used in the past [47-49].

The results of AAILs' $\mathrm{EC}_{50}$ value in contact with $V$. cholerae are considerably higher in many cases compared to $P$. aeruginosa, even though both of them are gram-negative bacteria. By observing the obtained results for $P$. aeruginosa and $V$. cholerae, Cho[Trp] and $\mathrm{Cho}[\mathrm{Tyr}]$ are demonstrating the least biocompatibility compared to others based on their $\mathrm{EC}_{50}$ value. The remaining AAILs show acceptable range of biocompatibility and to be categorized as practically harmless; furthermore, Cho[Ser] and Cho[Ala] with an $\mathrm{EC}_{50}$ value of higher than $1000 \mathrm{mg} / \mathrm{L}$ are branded as harmless to $P$. aeruginosa and V. cholerae respectively. The toxicity effects of ILs towards microorganisms relates to a common cellular structural process. The interaction between the ILs and bacteria cells leads to cellular membrane disruption which then causes membrane-bound protein disruption. The $\mathrm{EC}_{50}$ values show that the effect of AAILs on gram-negative bacterium is considerably lower than the gram-positive bacteria. By incubating the same AAILs with $P$. aeruginosa (gram-negative), majority of the tested AAILs show comparably high $\mathrm{EC}_{50}$ (less toxic) values unlike the gram-positive bacteria. The effect of Cho[Asp] (906 mg/L), Cho[Glu] $(800 \mathrm{mg} / \mathrm{L})$ and Cho[Met] $(715 \mathrm{mg} / \mathrm{L})$ on $P$. aeruginosa are very similar to their effect on $V$. cholerae. The $\mathrm{EC}_{50}$ values are relatively higher, meaning they are less toxic towards $P$. aeruginosa. This is due to the presence of an outer peptidoglycan layer adjutant to the cytoplasmic membrane of the cell. This scenario decreases permeability of the ILs into the cells, making it able to withstand the presence of ILs into its surroundings.

Figure 2 depicts a visual comparison of biocompatibility in terms of bubble size. From the figure it can be clearly observed that Cho[Trp] has the most toxic impact on the tested bacteria (based on the small size of the bubble). Results show that changing anion produces different biocompatibility characteristics for AAILs. Gram-positive bacteria are more sensitive to these changes compared to gram-negative types. Cho[Asp] revealed acceptable biocompatibility and on the other hand Cho[Trp] and Cho[Tyr] showed less biocompatibility towards all the tested bacteria. This is due to the presence of an aromatic ring in structure of the anion which leads to higher toxicity to the tested microorganism [50,51].

The molecular weight of the anion $(\mathrm{g} / \mathrm{mol})$ follows the order of Ala $<$ Ser $<$ Glu $<$ Met $<$ His $<$ Phe $<$ Arg $<$ Tyr $<$ Trp; with Cho[Trp] having the largest molecular weight. By comparing the $\mathrm{EC}_{50}$ values and the molecular weight of the anion molecules in the structure of AAILs, it can be seen that the smaller the value of the molecular weight, the lower the toxicity values which is also supported by [24]. As the anion molecular size increases either by chain length or presence of functional groups, the $\mathrm{EC}_{50}$ value of those AAILs decreases [52,53] which is a similar trend observed in this study. Therefore, the smaller and lighter

\begin{tabular}{|c|c|c|c|c|}
\hline \multirow{2}{*}{$\begin{array}{l}\text { lonic } \\
\text { Liquid }\end{array}$} & S. aureus & $\begin{array}{c}\text { B. } \\
\text { licheniormis }\end{array}$ & $P$. aeruginosa & V. cholerae \\
\hline & $\begin{array}{c}24 \mathrm{~h} \mathrm{EC}_{50}(\mathrm{mg} / \mathrm{L}) \\
\text { (low-high) }\end{array}$ & $\begin{array}{c}24 \mathrm{~h} \mathrm{EC}_{50} \\
\text { (mg/L) (low- } \\
\text { high) }\end{array}$ & $\begin{array}{c}24 \text { h EC } \\
\text { (mg/L) (low- } \\
\text { high) }\end{array}$ & $\begin{array}{c}24 \mathrm{~h} \mathrm{EC}_{50} \\
\text { (mg/L) } \\
\text { (low-high) }\end{array}$ \\
\hline [Cho][Ala] & $\begin{array}{c}547 \\
(218-1375)\end{array}$ & $\begin{array}{c}474 \\
(345-652)\end{array}$ & $\begin{array}{c}515 \\
(424-626)\end{array}$ & $\begin{array}{c}1120 \\
(923-1358)\end{array}$ \\
\hline [Cho][Ser] & $\begin{array}{c}716 \\
(554-925)\end{array}$ & $\begin{array}{c}395 \\
(355-466)\end{array}$ & $\begin{array}{c}1070 \\
(820-1395)\end{array}$ & $\begin{array}{c}912 \\
(760-1093)\end{array}$ \\
\hline [Cho][Asp] & $\begin{array}{c}882 \\
(446-1979)\end{array}$ & $\begin{array}{c}588 \\
(309-695)\end{array}$ & $\begin{array}{c}906 \\
(542-1514)\end{array}$ & $\begin{array}{c}940 \\
(717-1084)\end{array}$ \\
\hline [Cho][Glu] & $\begin{array}{c}231 \\
(171-310)\end{array}$ & $\begin{array}{c}366 \\
(300-478)\end{array}$ & $\begin{array}{c}800 \\
(655-975)\end{array}$ & $\begin{array}{c}813 \\
(589-1123)\end{array}$ \\
\hline [Cho][Met] & $\begin{array}{c}610 \\
(371-998)\end{array}$ & $\begin{array}{c}417 \\
(480-572)\end{array}$ & $\begin{array}{c}715 \\
(328-1256)\end{array}$ & $\begin{array}{c}695 \\
(563-856)\end{array}$ \\
\hline [Cho][His] & $\begin{array}{c}633 \\
(323-1242)\end{array}$ & $\begin{array}{c}290 \\
(233-372)\end{array}$ & $\begin{array}{c}609 \\
(430-864)\end{array}$ & $\begin{array}{c}743 \\
(553-998)\end{array}$ \\
\hline [Cho][Phe] & $\begin{array}{c}251 \\
(194-326)\end{array}$ & $\begin{array}{c}217 \\
(186-260)\end{array}$ & $\begin{array}{c}726 \\
(394-1597)\end{array}$ & $\begin{array}{c}792 \\
(584-1073)\end{array}$ \\
\hline [Cho][Arg] & $\begin{array}{c}212 \\
(167-268)\end{array}$ & $\begin{array}{c}298 \\
(190-485)\end{array}$ & $\begin{array}{c}577 \\
(385-863)\end{array}$ & $\begin{array}{c}640 \\
(375-1090)\end{array}$ \\
\hline [Cho][Tyr] & $\begin{array}{c}323 \\
(225-464)\end{array}$ & $\begin{array}{c}160 \\
(144-183)\end{array}$ & $\begin{array}{c}478 \\
(131-742)\end{array}$ & $\begin{array}{c}574 \\
(470-703)\end{array}$ \\
\hline [Cho][Trp] & $\begin{array}{c}203 \\
(141-291)\end{array}$ & $\begin{array}{c}194 \\
(170-224)\end{array}$ & $\begin{array}{c}280 \\
(137-572)\end{array}$ & $\begin{array}{c}381 \\
(310-470)\end{array}$ \\
\hline
\end{tabular}

Table 1: Mean effective concentration (EC50) of the AAILs towards different bacteria.

\begin{tabular}{|c|c|c|}
\hline Entry & lonic Liquid & Biodegradability (\%) 28 days \\
\hline 1 & [Cho][Ala] & $64.1 \pm 2.2$ \\
\hline 2 & [Cho][Met] & $65.1 \pm 3.9$ \\
\hline 3 & [Cho][Ser] & $71.1 \pm 3.2$ \\
\hline 4 & [Cho][His] & $72.5 \pm 3.0$ \\
\hline 5 & [Cho][Tyr] & $72.8 \pm 2.6$ \\
\hline 6 & [Cho][Phe] & $73.8 \pm 1.8$ \\
\hline 7 & [Cho][Asp] & $77.0 \pm 5.5$ \\
\hline 8 & [Cho][Arg] & $77.3 \pm 4.5$ \\
\hline 9 & {$[$ Cho][Glu] } & $83.5 \pm 2.0$ \\
\hline 10 & [Cho][Trp] & $85.8 \pm 9.4$ \\
\hline
\end{tabular}

Table 2: Biodegradability (\%) of the AAILs.

the anions are the more biocompatible the AAILs are. However, according to some authors the anions of IL do not affect the ecotoxicity but instead determines their physical and chemical properties which include solubility, viscosity and melting temperatures [54,55]. Recent studies indicate that the anion effect has been overlooked for it possibility to contribute to the overall toxicity [44]; focusing on fluorine as the anion which collectively played role in the toxicity of the ILs. The OECD guideline mentions that the studied compound must exceed the threshold mineralization efficiency of $60 \%$ (within 28 days) in order to be considered as "readily" biodegradable. Taking this gage into consideration, it can be concluded that all the studied AAILs can referred to as "readily" biodegradable. "Readily biodegradable" substances go through biodegradation in wastewater treatment plants or in natural water reservoirs within short terms and they are not persistent.

It is generally known that the incorporation of choline cation as well as carboxyl and amino groups in the anion highly improves the biodegradability of ILs $[24,37]$. However, a variation to biodegradability values indicate that the type of anion incorporated in the structure of AAILs has a vital effect in determining the quality of biodegradation. Also observed, the biodegradability of the AAILs improved as the size of the anion molecule increased. For AAILs with bigger anion molecules 


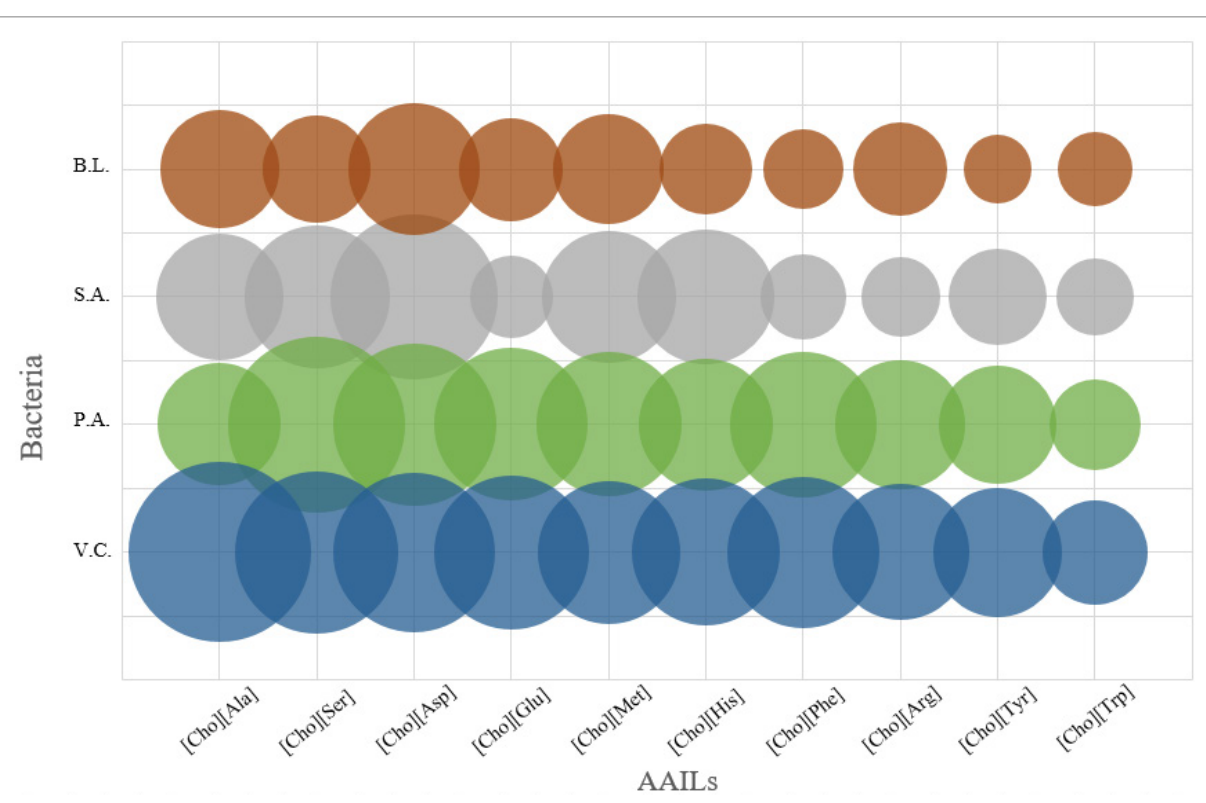

Figure 2: Impression of the AAILs' (X-axis) toxicity towards bacteria (Y-axis). The bigger diameter of bubble indicates safer AAILs.

such as L-Tryptophan (containing an indole ring functional group) the biodegradability was as high as $85.8 \%$. Heterocyclic indole functional group is known as an environmental pollutant which goes through biodegradation under sulfate reduction at high rates [56]. L-Histidine is also a relatively big molecule incorporated by an imidazole functional group but the biodegradability value of Cho[His] was about $72.5 \%$ since the imidazole functional group does not favor high biodegradation [37]. L-Phenylalanine incorporates a benzene ring and L-Tyrosine incorporates phenol as a functional group in their molecules. This has resulted in a difference in biodegradability values of Cho[Phe] (72.8\%) and $\mathrm{Cho}[\mathrm{Tyr}](73.8 \%)$. This can be explained through an extra oxygen atom that phenol functional group possesses [57].

Another relationship can be derived between biodegradability and the alkyl side chain length of anion is by comparing Cho[Asp] and Cho[Glu] (77\% and $83.5 \%$ biodegradation respectively). Longer alkyl side chain length of anion structure also helped with a higher biodegradability range. Since L-Glutamine has a longer side chain compared to L-Asparagine, the biodegradability values obtained for these AAILs suggest that the longer side chain length improves biodegradability; this is because the amount of oxygen required by the microbial consortia to degrade the larger compounds is higher. Cho[Met] and Cho[Arg] are another examples of this case. However presence of thioether functional group in L-Methionine is the reason for lower biodegradability of Cho[Met]. Also, L-Arginine has a guanidine functional group in its molecule that is proved to be susceptible to biodegradation [58]. Therefore, biodegradation is influenced by both size and side chain length of the anion molecule and is a strong factor of functional groups present in the molecular structure of anion. There is a rising concern on the link between biodegradability; stating that ILs with long alkyl chain are toxic but easily biodegradable [24,52]. However, this conflict can be put to rest when employing choline based amino acid ILs since the low toxicity correlates with high biodegradability values.

\section{Conclusion}

Eco-toxicity results of AAILs reveal that different anions impose different effects on microorganisms. The molecular structure of anion can be taken into analysis to justify their effect. It was found that bigger anion molecules were more toxic and smaller anion sizes improved the biocompatibility. It is necessary to mention that the type of microorganism is also an important factor in analyzing and concluding the toxicity of AAILs since each of the gram-negative and gram-positive bacteria showed different reactions to an individual IL. As it was expected from choline based AAILs to improve the toxicity, the obtained results met this expectation confirming that these ILs are at least "practically harmless" to various bacteria. The effect of anion molecule sizes in biodegradability concluded to have a direct effectlarger the anion molecule, greater the biodegradability.

\section{Acknowledgement}

Authors would like to thank the Centre of Research in Ionic Liquids (CORIL), Universiti Teknologi PETRONAS for their financial support.

\section{References}

1. Sivapragasam M, Moniruzzaman M, Goto M (2016) Recent advances in exploiting ionic liquids for biomolecules: Solubility, stability and applications. Biotechnology Journal 11: 1000-1013.

2. Losetty V, Sivapragasam M, Wilfred CD (2016) Recent advances and thermophysical properties of acetate-based protic ionic liquids. Chemical Sciences Journal.

3. Somers AE, Howlett PC, MacFarlane DR, Forsyth M (2013) A review of ionic liquid lubricants. Lubricants 1: 3-21.

4. $\mathrm{Pu} \mathrm{Y}$, Jiang $\mathrm{N}$, Ragauskas $\mathrm{AJ}$ (2007) Ionic liquid as a green solvent for lignin. Journal of Wood Chemistry and Technology 27: 23-33.

5. Pandey S (2006) Analytical applications of room-temperature ionic liquids: A review of recent efforts. Analytica Chimica Acta 556: 38-45.

6. Dewilde S, Dehaen W, Binnemans K (2016) lonic liquids as solvents for PPTA oligomers. Green Chemistry 18: 1639-1652.

7. Poliakoff M, Licence P (2015) Supercritical fluids: Green solvents for green chemistry? Philosophical transactions. Series A, Mathematical, Physical and Engineering Sciences 373.

8. Bianchini R, Cevasco G, Chiappe C, Pomelli CS, Rodríguez MJ (2015) Ionic liquids can significantly improve textile dyeing: An innovative application assuring economic and environmental benefits. ACS Sustainable Chemistry \& Engineering 3: 2303-2308. 
Citation: Yazdani A, Sivapragasam M, Levêque JM, Moniruzzaman M (2016) Microbial Biocompatibility and Biodegradability of Choline-Amino Acid Based Ionic Liquids. J Microb Biochem Technol 8: 415-421. doi: 10.4172/1948-5948.1000318

9. Ibrahim F, Moniruzzaman M, Yusup S, Uemura Y (2015) Dissolution of cellulose with ionic liquid in pressurized cell. Journal of Molecular Liquids 211: 370-372.

10. Muzart $J$ (2006) lonic liquids as solvents for catalyzed oxidations of organic compounds. Advanced Synthesis \& Catalysis 348: 275-295.

11. Visser AE, Swatloski RP, Griffin ST, Hartman DH, Rogers RD (2001) Liquid/ liquid extraction of metal ions in room temperature ionic liquids. Separation Science and Technology 36: 785-804

12. Palacio M, Bhushan B (2010) A review of ionic liquids for green molecular lubrication in nanotechnology. Tribology Letters 40: 247-268.

13. Elgharbawy AA, Alam MZ, Moniruzzaman M, Goto $M$ (2016) Ionic liquid pretreatment as emerging approaches for enhanced enzymatic hydrolysis of lignocellulosic biomass. Biochemical Engineering Journal 109: 252-267.

14. Lozano P, Bernal JM, Garcia-Verdugo E, Sanchez-Gomez G, Vaultier M, et al. (2015) Sponge-like ionic liquids: A new platform for green biocatalytic chemical processes. Green Chemistry 17: 3706-3717.

15. Moniruzzaman M, Ono T (2013) Separation and characterization of cellulose fibers from cypress wood treated with ionic liquid prior to laccase treatment. Bioresource Technology 127: 132-137.

16. Moniruzzaman M, Ono T (2012) Ionic liquid assisted enzymatic delignification of wood biomass: a new 'green' and efficient approach for isolating of cellulose fibers. Biochemical Engineering Journal 60: 156-160.

17. Guohua YTG (2012) lonic Liquids in Pharmaceuticals. Progress in Chemistry 10: 006

18. Ferraz R, Branco LC, Prudencio C, Noronha JP, Petrovski Ž (2011) lonic liquids as active pharmaceutical ingredients. Chem Med Chem 6: 975-985

19. Moniruzzaman M, Goto M (2011) Ionic liquids: future solvents and reagents for pharmaceuticals. Journal of Chemical Engineering of Japan 44: 370-381.

20. Moniruzzaman M, Tamura M, Tahara Y, Kamiya N, Goto M (2010) Ionic liquid-in-oil microemulsion as a potential carrier of sparingly soluble drug: Characterization and cytotoxicity evaluation. International Journal of Pharmaceutics 400: 243-250.

21. Malhotra SV (2010) Ionic liquid applications: Pharmaceuticals, therapeutics and biotechnology. American Chemical Society 1038: 81-86.

22. Hough-Troutman WL, Smiglak M, Griffin S, Reichert WM, Mirska I, et al. (2009) Ionic liquids with dual biological function: Sweet and anti-microbial, hydrophobic quaternary ammonium-based salts. New Journal of Chemistry 33: 26-33.

23. Fukaya Y, lizuka Y, Sekikawa K, Ohno H (2007) Bio ionic liquids: Room temperature ionic liquids composed wholly of biomaterials. Green Chemistry 9: 1155-1157.

24. Hou XD, Liu QP, Smith TJ, Li N, Zong MH (2013) Evaluation of toxicity and biodegradability of cholinium amino acids ionic liquids. PLoS One 8 : e59145.

25. Gathergood N, Garcia MT, Scammells PJ (2004) Biodegradable ionic liquids: Part I. Concept, preliminary targets and evaluation. Green Chemistry 6: 166-175.

26. Lopes JM, Paninho AB, Môlho MF, Nunes AV, Rocha A et al. (2013) Biocompatible choline based ionic salts: Solubility in short-chain alcohols. The Journal of Chemical Thermodynamics 67: 99-105.

27. Plaquevent JC, Levillain J, Guillen F, Malhiac C, Gaumont AC (2008) Ionic liquids: New targets and media for $\alpha$-amino acid and peptide chemistry. Chemical reviews 108: 5035-5060

28. Ohno H, Fukumoto K (2007) Amino acid ionic liquids. Accounts of Chemical Research 40: 1122-1129.

29. Gouveia W, Jorge TF, Martins S, Meireles M, Carolino M, et al. (2014) Toxicity of ionic liquids prepared from biomaterials. Chemosphere 104: 51-56.

30. Rogers RD, Brennecke JF, Seddon KR (2007) lonic liquids IV: Not just solvents anymore. American Chemical Society. 975: 101-120.

31. Pham TPT, Cho CW, Min J, Yun YS (2008) Alkyl-chain length effects of imidazolium and pyridinium ionic liquids on photosynthetic response of Pseudokirchneriella subcapitata. Journal of Bioscience and Bioengineering 105: 425-428.
32. Tao GH, He L, Sun N, Kou Y (2005) New generation ionic liquids: Cations derived from amino acids. Chemical communications: 3562-3564

33. Davis S, Hada S, Herring R, Eden M (2014) Characterization based reverse design of ionic liquids. Computer Aided Chemical Engineering: 285-290.

34. Tang F, Zhang Q, Ren D, Nie Z, Liu Q, Yao S (2010) Functional amino acid ionic liquids as solvent and selector in chiral extraction. Journal of Chromatography A 1217: 4669-4674.

35. Hu S, Jiang T, Zhang Z, Zhu A, Han B, et al. (2007) Functional ionic liquid from biorenewable materials: Synthesis and application as a catalyst in direct aldo reactions. Tetrahedron Letters 48: 5613-5617.

36. Egorova KS, Seitkalieva MM, Posvyatenko AV, Ananikov VP (2015) An unexpected increase of toxicity of amino acid-containing ionic liquids. Toxicology Research 4: 152-159.

37. Boethling RS, Sommer E, DiFiore D (2007) Designing small molecules for biodegradability. Chemical reviews 107: 2207-2227.

38. Higdon J (2003) Micronutrient information center. Linus Pauling Institute.

39. Chemicals Inspection and Testing Institute (1992) Biodegradation and bioaccumulation data of existing chemicals based on the CSCL Japan. Japan Chemical Industry Ecology-Toxicology and Information Center.

40. Weaver KD, Kim HJ, Sun J, MacFarlane DR, Elliott GD (2010) Cyto-toxicity and biocompatibility of a family of choline phosphate ionic liquids designed for pharmaceutical applications. Green Chemistry 12: 507-513.

41. Petkovic M, Ferguson JL, Gunaratne HN, Ferreira R, Leitao MC, et al. (2010) Novel biocompatible cholinium-based ionic liquids-toxicity and biodegradability. Green Chemistry 12: 643-649.

42. Ready Biodegradability (1992) OECD guidelines for testing of chemicals 301 A-F. Organisation for Economic Co-operation and Development, Paris.

43. Passino DRM, Smith SB (1987) Quantitative structure-activity relationships (QSAR) and toxicity data in hazard assessment. QSAR in Environmental Toxicology-II: 261-270.

44. Ventura SP, Marques CS, Rosatella AA, Afonso CA, Gonçalves F, et al. (2012) Toxicity assessment of various ionic liquid families towards Vibrio fischer marine bacteria. Ecotoxicology and Environmental Safety 76: 162-168.

45. Megaw J, Busetti A, Gilmore BF (2013) Isolation and characterisation of 1-alkyl3-methylimidazolium chloride ionic liquid-tolerant and biodegrading marine bacteria. PloS one 8: e60806.

46. Garcia MT, Gathergood N, Scammells PJ (2005) Biodegradable ionic liquids Part II. Effect of the anion and toxicology. Green Chemistry 7: 9-14.

47. Coleman D, Špulák M, Garcia MT, Gathergood N (2012) Antimicrobial toxicity studies of ionic liquids leading to a 'hit' MRSA selective antibacterial imidazolium salt. Green Chemistry14: 1350-1356.

48. Pernak J, Syguda A, Janiszewska D, Materna K, Praczyk T (2011) lonic liquids with herbicidal anions. Tetrahedron 26:4838-44.

49. Busetti A, Crawford DE, Earle MJ, Gilea MA, Gilmore BF, et al. (2010) Antimicrobial and antibiofilm activities of 1-alkylquinolinium bromide ionic liquids. Green Chemistry 12: 420-425.

50. Foulet A, Ghanem OB, El-Harbawi M, Lévêque JM, Mutalib MA, et al. (2016) Understanding the physical properties, toxicities and anti-microbial activities of choline-amino acid-based salts: Low-toxic variants of ionic liquids. Journal of Molecular Liquids 221: 133-138.

51. Bisht M, Jha I, Venkatesu P (2016) Comprehensive evaluation of biomolecular interactions between protein and amino acid based-ionic liquids: A comparable study between $[\mathrm{Bmim}][\mathrm{Br}]$ and $[\mathrm{Bmim}][\mathrm{Gly}]$ ionic liquids. Chemistry Select. 1: 3510-3519.

52. Bubalo MC, Hanousek K, Radošević K, Srček VG, Jakovljević T, et al. (2014) Imidiazolium based ionic liquids: Effects of different anions and alkyl chains lengths on the barley seedlings. Ecotoxicology and environmental safety 101 116-123.

53. Wang H, Malhotra SV, Francis AJ (2011) Toxicity of various anions associated with methoxyethyl methyl imidazolium-based ionic liquids on Clostridium sp. Chemosphere 82: 1597-1603.

54. Biczak R, Bałczewski P, Pawłowska B, Bachowska B, Rychter P (2014) Comparison of phytotoxicity of selected phosphonium ionic liquid. Ecological Chemistry and Engineering S21: 281-295. 
Citation: Yazdani A, Sivapragasam M, Levêque JM, Moniruzzaman M (2016) Microbial Biocompatibility and Biodegradability of Choline-Amino Acid Based Ionic Liquids. J Microb Biochem Technol 8: 415-421. doi: 10.4172/1948-5948.1000318

55. Stolte S, Arning J, Bottin-Weber U, Matzke M, Stock F, et al. (2006) Anion effects on the cytotoxicity of ionic liquids. Green Chemistry 8: 621-629.

56. Jothimani $P$, Kalaichelvan G, Bhaskaran A, Selvaseelan DA, Ramasamy $K$ (2003) Anaerobic biodegradation of aromatic compounds. Indian Journal of Experimental Biology 41: 1046-1067.
57. Vogt C, Kleinsteuber S, Richnow HH (2011) Anaerobic benzene degradation by bacteria. Microbial Biotechnology 4: 710-724.

58. O'Malley LP, Collins AN, White GF (2006) Biodegradability of end-groups of the biocide polyhexamethylenebiguanide (PHMB) assessed using mode compounds. Journal of Industrial Microbiology and Biotechnology 33: 677-684. 